\title{
The Relationship Between Organizational Ethical Culture And The Ethical Behavior Of Employees: A Study Of Accounting And Finance Professionals In The Insurance Industry Of United States
}

\author{
Akwasi Ampofo, Nova Southeastern University \\ Bahaudin Mujtaba (Email: Mujtaba@nova.edu), Nova Southeastern University \\ Frank Cavico, Nova Southeastern University \\ Laura Tindall, Nova Southeastern University
}

\begin{abstract}
This study explores the relationship between organizational ethical culture and ethical behavior of accounting/finance professionals working in the insurance industry in the United States. Results of 100 respondents in five different insurance organizations suggest that there is a significant relationship between organizational ethical culture and ethical behavioral intentions given bad debt write off and insider trading ethical vignettes. This was consistent with prior research findings that written (formal) and unwritten (informal) organizational policies significantly affect employees' ethical decision-making (Sims and Keon, 2000 \& 1997). Key (1999) also argued that organizational culture sends messages as to sanctioned and unsanctioned behavior.
\end{abstract}

The Relationship between Organizational Ethical Culture and Ethical Behavior

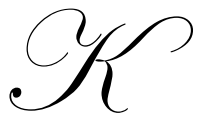

ey (1999) argued that ethical behavior by business leaders send messages on sanctioned and unsanctioned behavior. Smith (2003) pointed out that unethical behavior is a dagger in the heart, and lack of integrity have led to the fall of giant corporations such as Enron, MCIWorldcom, Adelphia, and Global Crossing. The goal of this study is to empirically investigate the relationship between organizational ethical culture and ethical behavioral intentions among accounting/finance professionals in the insurance industry in the United States of America.

Ampofo et al, (2004), in their article titled "Organizational Ethical Culture: A Significance Determinant of Ethical Behavior," mentioned Schein's (1992, p.12) definition of culture which is a pattern of shared foundational assumptions that a group learns as it solves its problems of external adaptation, and internal integration, that works well enough to be considered valid, and, therefore, to be taught to new members as the correct way to perceive, think, and feel in relation to those problems. Ampofo et al (2004), further used Key's (1999) description of organizational ethical culture defined as the as beliefs about the ethics of an organization, which are shared by its members and may be logically conceptualized on a continuum bounded at one end by unethical companies and at the other, highly ethical companies. Moreover, the concepts of organizational ethical culture and ethical behavior have generated greater interest among researchers, educators, practitioners, and the general public post-Enron, possibly, due to the catastrophic consequences of the corporate failures. Following the Associated Press (2002) report that the Texas State Employees Retirement Fund (TSERF) lost an estimated \$63 million in Enron investments, the investing public does not need an analyst to see why business ethics is a "hot" topic in practice and education. Enron's bankruptcy filling has been portrayed as the result of accounting fraud and greed (Culp and Hanke, 2003). Further, the perceived role of accounting firms, such as Arthur Andersen in the corporate 
"downpour," has tarnished the Certified Public Accountant (CPA) "brand" by weakening its very foundation, its integrity. For instance, the American Institute of CPAs (AICPA) research in 2003 revealed that one-fifth of business decision-makers see CPAs among most to blame for the corporate accounting scandals. AICPA (2003) further stated that forty percent of business decision-makers (half of investors) think CPAs are willing to cut corners for clients. This study argues that business ethics training, and practice provides intervention and fosters the institutionalization of ethical cultures in organizations.

The theory of planned behavior (hereafter: TPB) from Ajzen's (1991) study is used as an integrative tool to attain the research objectives. TPB states that behavior is determined by intentions, which in turn, is determined by attitude toward behavior [e.g. attitudes, beliefs], subjective norm [e.g. influence of peers, social and professional groups], and perceived behavioral control [e.g. control beliefs] (Ampofo et al, 2004). The eclectic discipline of business administration has benefited immensely from using TPB in ethical decision-making research. For instance, scholars have used the theory to investigate various behaviors (e.g. tax compliance [Bobek and Hatfield, 2003], business ethics and corporate social policy [Epstein, 1998], ethical problems in public accounting [Finn, 1998], and academics commitment to ethics [Gunz and McCutcheon, 1998]). The theory section of the present study further explicates TPB and uses two ethical scenarios on bad debt write off (scenario 1), and insider trading (scenario 2) to operationalize ethical behavioral intention.

Furthermore, insurance industry accounting/finance professionals provides an ideal population for ethics research following compliance activities associated with regulation such as Sarbanes Oxley Act (2002), and industry best practices. Most of the insurance companies have a code of ethics, and do offer ethics training for the employees including the leadership. These professionals may also ascribe to code of ethics of one or more professional organizations such as the American Institute of Certified Public Accountants (AICPA) or Institute of Management Accountants (IMA), and have an incentive to protect their professional reputation and licensing status. Arguably, the educational preparation, continuing professional education (CPE), and legal implications of unethical conduct make the professionals ideal to study. As a practical matter therefore, in this study, we focus on the insurance industry accounting/finance professionals. The next section reviews the literature on organizational ethical culture, TPB, business ethics, and provides motivation for the development of research hypotheses. The validity and reliability of the research instruments used to operationalize the constructs are examined. We perform data analysis, report the results, discuss limitations, implications of the study, and make recommendations for future research.

\section{Literature Review}

This section discusses the literature on the theory of planned behavior, ethical decision-making, and organizational ethical culture. It also provides the motivation for the development of the research hypothesis.

\section{Theory of Planned Behavior}

The theory of planned behavior has its roots in the theory of reasoned action, which was derived from psychology (Ampofo et al, 2004). The theory of planned behavior (TPB) models behavioral intentions (BI) as depending on three factors: (1) attitude toward the behavior

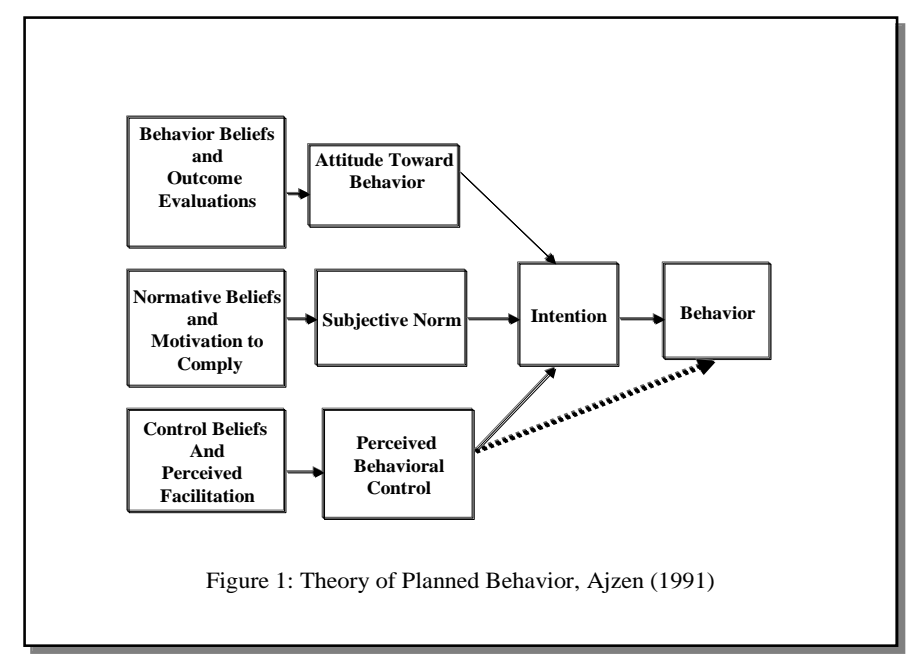
(ATB); (2) subjective norms (SN); and (3) perceived behavioral control (PBC). Bobek and Hatfield (2003) noted that each of the determinants of behavioral intention (i.e. ATB, SN, and PBC) is itself a function of an individual's salient beliefs. Several social psychology studies have validated the TPB in a variety of contexts (Bobek and Hatfield, 2003; Etherington and Hill, 1998). Bobek and Hatfield (2003) referred to TPB's ability to predict 
dishonest actions by college students (specifically, cheating on an exam, shoplifting, and lying). Figure 1 is a model diagram of Theory of Planned Behavior (TPB) showing the relationship among variables.

\section{Ethical Behavioral Intention}

Behavioral intention (BI) is the dependent variable in this study. Brown (1999) defined intention (I) as the subjective probability that an individual will perform a behavior. Intention is very difficult to measure if it is not expressed into an act. Behavior (B) is an act that takes place as a result of an intention. However, this definition does not account for impulsive behavior, such as buying an item in a mall that one did not intend to purchase. Nonetheless, ethical intention is the most direct measure of ethical behavior. This is so, because it is less likely to observe unethical behavior directly in the light of threats of incrimination, and other undesirable consequences. Several researchers including Ajzen and Fishbein (1980), Dahlin (2000), and Gibson and Frakes (1998) have used intention as a direct measure of behavior. Consistent with prior research (Dahlin, 2000), in this study, ethical decision-making is synonymous with ethical behavioral intention. Mujtaba (1997) and other researchers argue that it is more difficult to accurately measure ethical behavior because of the sensitive nature of ethics. Though not the focus of this study, the following paragraphs provide brief explanation of some of the key components of TPB.

Brown (1999) defined attitude towards behavior (ATB) as the degree to which a person has favorable or unfavorable evaluation of a behavior. Underlying attitude refers to behavior beliefs as well as evaluations of outcomes (Ajzen and Fishbein, 1980). For instance, an accountant who believes a behavior to be unethical and one which carries severe reprimand, including exclusion from professional membership, is likely to have an unfavorable attitude towards the behavior. Several researchers including Ajzen and Fishbein (1980), Doll and Ajzen (1992), Fraedrich and Ferrell (1992), Peterson (2002), and Street (1998) treat attitude towards behavior as a significant predictor of behavioral intentions.

Ajzen (1991) describes subjective norms (SN) as the influence of referent others. Bobek and Hatfield (2003) described subjective norms as a person's beliefs about whether specific individuals or groups approve or disapprove of the individual performing a specific behavior, and to what extent the individual is motivated to conform with these other individuals or groups. Subjective norms (peer pressure) can be assessed directly or by considering the fundamental beliefs (referent beliefs) that underlie an individual's judgment of subjective norms (Bobek and Hatfield, 2003).

In the TPB, perceived behavioral control (PBC) refers to the degree of control an individual perceives s/he has to engage in a particular behavior. More specifically, control beliefs, the fundamental determinants of perceived behavioral control, refer to an individual's beliefs regarding the presence or absence of resources and opportunities, as well as the obstacles and impediments to perform the specific behavior in question (Bobek and Hatfield, 2003). Prior researchers, such as Gibson and Frakes (1997) and Etherington and Hill (1998), found PBC as a significant determinant of ethical behavior of Certified Management Accountants (CMAs).

\section{Organizational Ethical Culture}

Organizational Ethical Culture (OEC) is an independent variable in this study. Key (1999) defined organizational ethical culture as the ethical consideration of fairness, virtue, rights, utilitarianism, and justice in decision-making, and routine business practices of an organization. Organizational ethical culture embodies the extent to which ethical behavior is encouraged and rewarded in an organization. Culture may be individual, societal, or organizational (Hoftstede, 1998). Key (1999) described organizational ethical culture as the ethical aspects of an organization's culture. Trevino et al. (1986) and Key (1999) measured organizational ethical culture using the Ethical Culture Questionnaire (ECQ). The ECQ questions are not based on the two scenarios, but on the perception of each respondent of the ethical culture of company s/he worked for at the time of the study. 


\section{Prior Research on Ethical Behavior}

In a review of ethical decision-making research, Geriesh (2003) examined organizational culture and fraudulent financial reporting, and found that companies that have a history of corporate illegal activities are more likely to issue fraudulent financial statements. Moreover, Smith (2003) noted that founders and board members owned a significant proportion of companies that committed fraud. The Committee on Sponsoring Organizations (COSO) examined seventy-two cases in 1999. It found that the CEO appeared to be associated with the fraud in most cases. There also appeared to be an increase in fraud when insiders or others with significant ties to the company dominated the company's boards of directors. In addition, Smith (2003) notes that no company, regardless of size, is immune from fraud, and that successful crime leads to more crimes. There is a "slippery slope" of illegal behavior that begins with minor violations and develops into a culture that sanctions such behavior (Geriesh, 2003).

\section{Research Hypotheses for this Study}

Scholars have described culture as "the way we do things around here." Key (1999) posits that organizational ethical culture sends messages as to sanctioned and unsanctioned behavior from top management. Most organizations in the insurance industry train their employees on its ethical values (i.e. intervention), which become institutionalized over time. The organizational ethical culture therefore becomes a big part of the shared beliefs, and guiding principles that influence employee actions (Reigle, 2001). Reasonably, one would expect that the core ethical values and beliefs that underpin organizational ethical culture be related to the actions, deeds and intentions of those who share in that culture. Stated formally the hypothesis in the alternate and null forms is as follows:

Alternate Hypothesis. $\mathrm{Ha}_{1}$ : There is a relationship between organizational ethical culture and ethical behavioral intention of accounting/finance professionals in the insurance industry in U.S.A.

Null Hypothesis. $\mathrm{Ho}_{1}$ : There is not a relationship between organizational ethical culture and ethical behavioral intention of accounting/finance professionals in the insurance industry in U.S.A.

\section{Methodology}

In this study, a self-administered questionnaire design was used for gathering data. The subjects, selected in a convenience sample, were given a general statement concerning the reason for the study: "The purpose of this study is to determine the relationship between organizational ethical culture and ethical behavior." Subjects were asked a series of demographic questions, as well as, questions about their organization's ethical culture, and ethical behavioral intention given two vignettes on bad debt write off and insider trading. The respondents were then asked to complete the questionnaires, following the directions given for each section. They were assured of anonymity and asked to respond candidly. The data reported in this study were gathered as a small part of a larger study. The respondents had to meet the following criteria to qualify for inclusion in the sample: (a) currently employed full time as an accounting/finance professional; (b) has a bachelor's degree or professional certification in accounting or finance; and (c) has been working for the current organization for at least one year.

A sample of 100 accounting/finance professionals working in five national insurance companies was obtained to test hypothesis 1 . Of these professionals, 20 worked in each of the five organizations. The use of organizational contacts improved participation and increased the response rate to $40 \%$. To guarantee anonymity, each questionnaire had a stamped addressed envelope that respondents were asked to seal before returning the completed questionnaire either directly to the author or organizational contact for forwarding to the author. The average age of the respondents was 35.34 years (S.D. $=8.39)$ with average years of accounting experience of 9.58 years (S.D. $=5.62)$. The respondents were mostly males $(63 \%)$, with bachelor degrees $(71 \%)$ as their highest level of education, and had earned the Certified Public Accountant (39\%) professional designation.

"Ethical behavioral intention" was measured using standard measures of intention used by Ajzen and Fishbein (1980), Gibson and Frakes (1997), Bobek and Hatfield (2003). Consistent with prior research, two ethical 
scenarios on bad debt write off, and insider trading were used to opertationalize ethical behavioral intention (Gibson and Frakes, 1997; Bobek and Hatfield, 2003). Importantly, engaging in insider trading, and failing to write off aged accounts receivable are unethical behavior [unethical conduct] because the former is against spirit and substance of insider trading laws, and the latter is against Rule 203 of the AICPA Code of Conduct on departure from GAAP. On a 7-point Likert scale, respondents can choose to disagree (1 through 3), neither agree nor disagree (4), or agree (5 through 7), with specific statements measuring each construct given the scenarios. A higher score represents a more ethical behavioral intention and vice versa. Specific items that are reversed coded within the questionnaire were corrected before data analysis to ensure that the scales are uni-dimensional, a necessary condition for reliability. As an example, one statement used to measure BI in this study is: I would feel guilty if I engaged in [unethical conduct]. On a 1-7 Likert scale, a higher score (agree) implies more ethical behavioral intention and vice versa (disagree). The questionnaire has been validated several times in empirical research (Gibson and Frakes, 1997; Dahlin, 2000).

"Organizational ethical culture" was measured using the Ethical Culture Questionnaire (ECQ). On a 1-7 Likert scale, the respondents provided information on their perception of their organizational ethical culture. A higher score (5 to 7 ) indicates a more ethical organizational culture and vice versa (3 to 1). A score of 4 indicates that the respondent neither agree nor disagree with the measure of organizational ethical culture. One item: "My coworkers commonly engage in unethical behavior," is reverse-coded and was corrected prior to data analysis. Key (1999) and Trevino et al. (1986) have the alpha of the ECQ to be above .90, which is reliable given the .70 alpha cut off level recommended by Sims (2000), and Nunnally (1978). Key (1999) argued that the Ethical Culture Questionnaire measures individual perception of an organization's ethical culture.

The Accounting Ethics Questionnaire (AEQ) includes instructions, items measuring the variables, the two ethical scenarios, and some demographic information. The Institutional Review Board of Nova Southeastern University approved the Accounting Ethics Questionnaire (AEQ) before distribution to any participant. The survey contained 20 items measuring organizational ethical culture, and 4 items measuring ethical behavioral intentions, given the two ethical vignettes on bad debt write off, and insider trading. Some demographic items were also included in the survey along with specific instructions. A total of 250 surveys were distributed, 50 each to the five organization's internal representative, who sought and obtained permission to conduct the accounting ethics survey from appropriate organizational heads. To obtain organizational buy-in, and encourage voluntary participation, the accounting ethics survey was positioned as a research study to enhance the integrity of the accounting profession, and encourage ethics research and education of future business leaders. The organizations were concentrated around Connecticut, Philadelphia, Colorado, Virginia, and North Carolina.

The respondents were instructed to either return the completed surveys in the stamped addressed envelop either directly to the author or the organizational contact. As such, some surveys were returned singly or in bulk from the organizational contracts. Data was entered into a statistical software package known as SPSS and checked for clerical accuracy.

\section{Results of the Study}

A total of 100 surveys were returned by predetermined cut-off dates resulting in a response rate of $40 \%$, which is higher than the business ethics research average of about 30\% reported by Randall and Gibson (1990). Typical prior response rates were Dubinsky and Loken, 1989 [41\%], Randall and Gibson, 1990 [33\%], Gibson and Frakes, 1997 [26.7\%], and Etherington and Hill, 1998 [33.9\%]. Descriptive statistics as well as the reliability (see Table 1) of the scales used to measure the constructs are provided below. The Cronbach's alpha for every scale was above the .70 levels recommended by Nunnally (1978) and Sims (2000). Table 2 provides inter-correlations on variables for testing the hypothesis. It is important to note that ethical behavioral intention is broken down by scenarios 1,2 and the combined scenarios 1 and 2 . 
Table 1- Descriptive Statistics

\begin{tabular}{lccc}
\hline Variable & Mean & Standard Deviation & Cronbach's Alpha \\
\hline Organizational Ethical Culture & 5.55 & .770 & .8749 \\
Ethical Behavioral Intention 1 & 6.07 & 1.075 & .7518 \\
Ethical Behavioral Intention Scenario 2 & 5.86 & 1.073 & .7204 \\
Ethical Behavioral Intention Scenario 1 \&2 & 5.98 & .953 & .8076 \\
\hline
\end{tabular}

Table 2- Inter-correlations

\begin{tabular}{lcccc}
\hline & $\begin{array}{c}\text { Ethical Behavioral } \\
\text { Intention Scenario 1 }\end{array}$ & $\begin{array}{c}\text { Ethical Behavioral } \\
\text { Intention Scenario 2 }\end{array}$ & $\begin{array}{c}\text { Ethical Behavioral } \\
\text { Intention Scenarios 1 \& 2 }\end{array}$ & $\begin{array}{c}\text { Organizational } \\
\text { Ethical Culture }\end{array}$ \\
\hline $\begin{array}{l}\text { Ethical Behavioral } \\
\text { Intention Scenario 1 }\end{array}$ & 1 & $.525(* *)$ & $.799(* *)$ & $.282(* *)$ \\
$\begin{array}{l}\text { Ethical Behavioral } \\
\text { Intention Scenario 2 }\end{array}$ & $.525(* *)$ & 1 & $.827(* *)$ & $.461(* *)$ \\
$\begin{array}{l}\text { Ethical Behavioral } \\
\text { Intention Scenarios 1 \& 2 }\end{array}$ & $.799(* *)$ & $.827(* *)$ & 1 & $.442(* *)$ \\
$\begin{array}{l}\text { Organizational Ethical } \\
\text { Culture }\end{array}$ & $.282(* *)$ & $.461(* *)$ & $.442(* *)$ & 1 \\
\hline$* *$ Correlation is significant at the 0.01 level (2-tailed) & & & \\
\hline
\end{tabular}

** Correlation is significant at the 0.01 level (2-tailed).

Hypothesis 1 stated that there is a relationship between organizational ethical culture and ethical behavioral intentions of accounting/finance professionals in the insurance industry in U.S.A. The results of correlation test of 100 respondents indicate that there is a significant correlation between organizational ethical culture and ethical behavioral intentions in scenario $1(\mathrm{p}=.004)$, scenario $2(\mathrm{p}=.000)$, and scenarios 1 and 2 combined $(\mathrm{p}=.000)^{1}$. The average organizational ethical culture was $5.55(\mathrm{SD}=.770)$, and the average behavioral intention scores were 6.07 $(\mathrm{SD}=1.075)$ and $5.86(\mathrm{SD}=1.073)$ for scenarios 1 and 2 respectively. Interestingly, positive correlations were found between organizational ethical culture and ethical behavioral intention at $28.2 \%$ (scenario 1 ), $46.1 \%$ (scenario 2 ), and $44.2 \%$ (scenarios 1 and 2 combined). This implies that the more ethical the organizational culture, the more likely accounting/finance professional would make ethical decisions, other things being equal. Related to scenarios, the results suggest that more ethical organizational cultures are likely to write off the bad debt this year (i.e. not postpone the write off to next year [scenario 1]), and less likely to engage in insider trading (scenario 2). Since these probability levels are below the cut-off point of 5\%, hypothesis 1 is accepted given scenarios 1, and 2 (see Tables 2).

\section{Discussion of the Results}

Hypothetical ethical scenario 1 is concerned with postponing accounts receivable write off (bad debt write off) to next year in order to maximize profits and materially overstate assets by $\$ 10$ million. The scenario indicated the tremendous pressure from the Chief Executive Officer (CEO) for the accountant/finance professional (CFO) to engage in this unethical behavior (i.e. postpone the bad debt write off), and potential consequence of unemployment of most of the employees including the CFO. Further, respondents were sensitized to the fact that postponing the bad debt write-off is inconsistent with GAAP and is in violation of the AICPA Standards of Ethical Conduct as "an act discreditable to the profession" (Mintz, 1997). Given this hypothetical scenario and question 21 (I would feel guilty if I postponed this adjusting entry until next year), $85 \%$ of the respondents agreed, 3\% disagreed, and 12\% neither agreed nor disagreed with the statement

Hypothetical scenario 2 presented the case of profiting from material nonpublic information by trading in shares (insider-trading). The scenario sensitized the respondents to the possibility of maximizing organizational profits and personal bonuses, as well as "improving" relationship with superior. Further, the respondents were made aware that insider-trading regulations prohibit trading in securities by relying on material nonpublic information.

\footnotetext{
${ }^{1}$ The combined scenario 1 and 2 is the average scores for scenarios 1 (bad debt write off) and 2 (insider trading).
} 
Given this hypothetical scenario and question 42 (I would feel guilty if I purchased $\mathrm{ABC}$ shares now), $80 \%$ of the respondents agreed, 7\% disagreed, and 13\% neither agreed nor disagreed with the statement. It is important to underscore that these results relate to a hypothetical scenario and that respondents gave their intention, the most direct measure of behavior.

It is important to note that some of the accounting/finance professionals disagreed to some extent with few of the questions measuring behavioral intention. Of special mention is the reverse coded question 24 and 28 in scenarios 1 and 2 respectively: I would want to engage in the [unethical behavior]. After correcting for the reverse coding (i.e. I would NOT want to postpone this adjusting entry until next year), 17\% disagreed, $8 \%$ neither agreed nor disagreed, $75 \%$ agreed with the statement in scenario 1 . In scenario 2, after correcting for the reverse coding (i.e. I would NOT want to purchase ABC shares now), 38\% disagreed, $14 \%$ neither agreed nor disagreed, $48 \%$ agreed with the statement in scenario 2. This implies that at least $38 \%$ of the respondents would engage in insider trading given scenario 2 .

Organizational ethical culture scores are summarized in Table 3. On a Likert scale of 1-7 (less ethical to more ethical), organization $\mathrm{B}$ received the highest average score of $5.95(\mathrm{SD}=.686)$. Organizations $\mathrm{D}$ followed with an average score of $5.60(\mathrm{SD}=.995)$. Organization A attained $5.55(\mathrm{SD}=.686)$. Organization $\mathrm{E}$ came in next with a score of $5.40(\mathrm{SD}=.503)$. Organization $\mathrm{C}$ scored the least with an average score of $5.25(\mathrm{SD}=.786)$. These measures give a mental picture of how employees perceived each of these organizations' ethical culture. Due to the effect of interactive factors such as age, experience, training and education, gender, certification, and theory of planned behavior constructs, it is highly inappropriate to draw conclusions only based on the average OEC scores.

Table 3- Descriptive Statistics on Organizational Ethical Culture

\begin{tabular}{ccccccccc}
\hline Organization & $\mathbf{N}$ & Mean & $\begin{array}{c}\text { Std. } \\
\text { Deviation }\end{array}$ & $\begin{array}{c}\text { Std. } \\
\text { Error }\end{array}$ & $\begin{array}{c}\mathbf{9 5 \%} \text { Confidence Interval } \\
\text { for Mean }\end{array}$ & $\begin{array}{c}\text { Minimum } \\
\text { Maximum }\end{array}$ \\
\hline Organization A & 20 & 5.55 & .686 & .153 & 5.23 & 5.87 & 5 & 7 \\
Organization B & 20 & 5.95 & .686 & .153 & 5.63 & 6.27 & 5 & 7 \\
Organization C & 20 & 5.25 & .786 & .176 & 4.88 & 5.62 & 3 & 6 \\
Organization D & 20 & 5.60 & .995 & .222 & 5.13 & 6.07 & 3 & 7 \\
Organization E & 20 & 5.40 & .503 & .112 & 5.16 & 5.64 & 5 & 6 \\
\hline Total & 100 & 5.55 & .770 & .077 & 5.40 & 5.70 & 3 & 7 \\
\hline
\end{tabular}

The OEC scores may be used to categorize companies' ethical cultures on a continuum of less to more ethical, though such a measure has several limitations. For example, further analysis of variance (ANOVA) revealed that organizations $\mathrm{B}$ and $\mathrm{C}$ had significant differences in the average OEC scores $(\mathrm{p}=.047$, Mean difference $=.70$ ), placing the two organizations at different points on the OEC continuum. However, the OEC measure does not consider the views of external stakeholders (e.g. major customers) perception of the companies involved. OEC is also highly perceptual in nature (Key, 1999). The demographic and other interactive factors must be held constant for apples-to-apples comparison among the organizations. Thus, the above results do not necessarily imply that one organization is more ethical than the other, but merely how each organization lie on the ethical culture continuum before taking into account interaction effects. Further studies are necessary to determine if there is a significant difference in the organizational ethical cultures including the effects of interacting factors.

The concept of organizational ethical culture is very abstract and highly perceptual in that its measurement ultimately relies on self-report (Key, 1999). The average organizational ethical couture scores were between 5.25 and 5.95 on a 1 (less ethical) to 7 (more ethical) Likert scale. However, due to the political nature of organizations and differences in respondents' perceptions, in the organizations, there is no consensus among the respondents as to its ethical culture. These results do not reveal agreement among accounting/finance professionals in organizations; 
rather they reveal ranges from unethical to very ethical within each organization. This implies that organizational ethical culture represents individual perception about the ethical aspects of an organization.

In this regard, as groups of accounting/finance professionals' form, each brings his/her own ethical culture that comes to bear on the collective cultures of other accounting/finance professionals within organizations. The last incidence an organization desires is an unethical culture to domineer the organization, destroy its integrity, threaten its very existence, and cost it, and society at large, billions. This is what happened to Enron, Arthur Andersen, and MCI WorldCom through a series of unethical practices. Thus, organizational ethical culture is too important a construct to be left at the mercy of employees. Organizations are encouraged to craft, invest in, monitor and improve upon their ethical culture. Some companies for example, preach and practice "respect and integrity" to every employee from day one.

Trevino et al. (1986) studied the relationship of organizational culture to ethical decision-making. Schein (1992) states that an organization's culture can influence how ethical decisions are made, and the pressure to adapt one's behavior to organizational culture may lead to unethical behavior. In 1986, Trevino found that cultures that are more democratic are associated with increased ethical behavior, including a greater willingness to take individual responsibility for behavior. Smith (2003) outlined the theory of differential association, which says illegal behavior is learned in direct or indirect association with those who already practice the behavior. Trevino et al. (1986) observed that when ethical behaviors are reinforced by the organizational culture, these behaviors increase and vice versa. Key (1999) argued that the ethical culture of an organization sends messages to employees regarding sanctioned or unsanctioned ethical decision-making.

\section{Implications of Research}

A number of important research and practical implications emerge from these findings. From a research perspective, this study extends the literature on ethical decision-making by accountants given workplace influences (e.g. pressure from boss, likelihood of layoff), professional obligations (e.g. GAAP, \& AICPA code), and accounting education level. In this regard, accounting/finance professionals should recognize and appropriately resolve ethical dilemmas as they encounter them. Probably more important is the issue of recognition and empowerment of those professionals when involved in an ethical decision-making.

From a professional enforcement standpoint, the results provide ample implications for ethics education, training, monitoring, and support among industry accountants. Professional judgment in an ethical scenario is allowed under the "realistic possibility standard," and an accountant should be prepared to defend a non-GAAP choice if challenged in a court of law. Moreover, the trend toward increased ethics training for accountants should continue. We suggest companies develop and enforce rigorous ethics training modules that use real life scenarios for their accountants. The AICPA should also enforce its code of ethics among its members. Accountants should follow ethical guidance even if "it hurts" (Jones, 2002). The internal mode of resolving ethical dilemmas by both the IMA and AICPA have come under some criticism that it is ineffective and proves to be too burdensome to the accountants. Both the AICPA and IMA are encouraged to seek alternate resolution avenues that are mutually beneficial to companies and accountants without undue disadvantage to the latter group.

Regulators such as the Public Company Accounting Oversight Board (PCAOB) should enforce the rules on audit engagements on public companies. Some see auditors as simply being caught between a rock and hard place. Yet others argue that one cannot bite the hand that feeds them, and auditor objectivity has repeatedly been impaired for various reasons. One recommendation would be for federally mandated set of auditors that audit public companies under the PCAOB mandate. Rotation of auditors, and no cross servicing rules also should be enforced. To stop companies from firing auditors for hard or soft reasons, auditor should be paid even if fired in the first five years of the audit.

Ethics education and training should permeate throughout business education. There is too much learning about profitability and too little talk about the basis of sustainable profitability: integrity, honesty, and trust are crucial aspects of lasting business relationships and continuity. Ethics education should re-emphasize and refocus 
on the basis of good character and civilization (respect, responsibility, integrity, concern and care, etc). Companies need working code of ethics that is taught and reinforced to all employees on a continuous basis. Ethical employees should be rewarded via performance appraisals; and, unethical practices should be denounced.

Academic research on ethics should continue to classify ethical scenarios and come up with predictive factors for use by all stakeholders. For example, from the findings of this study, ethical scenarios may be classified into three types. Firstly, regulated scenarios having legal consequences including imprisonment or expulsion from professional membership (scenario 2). Second is professionally mandated scenario with "substantial authoritative support" such as following GAAP or GAAS (scenario 1). Another category would be socially inappropriate behavior such as theft, cheating and the like. Recognizing the ethical dilemma one is encountering and applying a rational decision-making process are good initial steps to resolving the dilemma successfully.

Employment relationships can be improved if all parties are honest to one another. Lies and dishonesty can be very costly professionally and personally and the wise person learns to avoid such a consequence before it happens to them. Some also would go through a situation and then learn from it. Yet, others never seem to learn as they repeat the same behaviors when tempted! Nonetheless, ethics training and education is crucial for all.

Investor confidence and securities trading came under strong defects after the corporate American scandals. Culture and organizational ethical culture is fundamental and ingrained in people's beliefs and thought processes that significantly impact ethical decision-making. This research implies that companies and employees can boost investor confidence through ethical decision-making and consistent actions that consider the interests of all stakeholders.

\section{Limitations of Research}

Several limitations emerge when evaluating the study's results. First, the sensitivity of ethical behavior brings into question the honesty of responses. Gibson and Frakes (1997) stated that respondents may falsify responses if there are strict consequences from professional associations for stating the truth. In this regard, the scenario used depicted what the accountants "would do," not "what they did," in a similar circumstance. Behavioral intention rather than actual behavior was measured and used as a substitute for ethical decision-making in scenarios 1 and 2. However, in real life, not all intentions are acted upon to become decisions. Moreover, prior research has called into question the reliability of self-reported ethical behavioral intention and other TPB constructs (Ajzen and Fishbein, 1998; Gibson \& Frakes, 1997; Mujtaba, 1997)

Secondly, OEC is perception based, not factual. Thus correlating OEC and BI may be highly debatable for reasons cited above. The concept of organizational ethical culture is very abstract and highly perceptual in that its measurement ultimately relies on self-report (Key, 1999). However, due to the political nature of organizations and differences in respondents' perceptions in the five organizations, there is no consensus among the respondents as to its ethical culture. These results do not reveal agreement among accounting/finance professionals in organizations A, B, C, D or E; rather they provide evidence of ranges from unethical to very ethical within each organization. This implies that organizational ethical culture represents individual perception about the ethical aspects of an organization.

The insurance industry provides an ideal home for the study of accounting ethics given the corporate ethics trainings associated in compliance with the Health Insurance Portability and Accountability Act (1996), and Sarbanes Oxley (2002). As a result, the overall modal scores were 7 (scenario 1) and 6 (scenario 2), interpreted as extremely/very ethical. However, these very reasons for choosing the insurance industry pose a limitation for generalization of the study's results. We recommend that the study be replicated among different accountants in different industries and the results be compared to our findings.

Finally, age, years of accounting experience, and educational level, are significant predictors of ethical behavior. Correlating organizational ethical cultures among a heterogeneous group of accounting/finance professionals does not take into account these significant predictors. However, the study is not concerned with 
comparing ethical/unethical organizational cultures. Instead, the focus is on how the organizational ethical culture relates to ethical decision-making/behavior. Further studies that seek to compare organizational ethical cultures should hold the demographic variables constant due to interacting effects.

\section{Conclusion}

These results suggest three avenues of future research. The first is to assess whether individual ethical cultures are transformable by organizational ethical cultures. Perhaps ethical employees would contribute to ethical organizational cultures. The second important avenue of research is to replicate this study among accountants working in other industries or totally different group of professionals, such as nurses or IT professionals. Thirdly, other organizational constructs such as political nature, past history of Securities and Exchange Commission violations, and employee commitment may be correlated with behavior. It has long been suggested that individual self-report of ethical behavior is not very accurate (Key 1999). For this reason, short and relevant ethical vignettes, that reduce respondent fatigue, have been used increasingly to measure ethical behavior (Gibson \& Frakes, 1997).

A natural extension of the findings from this study coupled with the recent developments in corporate accounting scandals would be an empirical study of the relationship between company code of ethics and ethical behavior. This task would help determine the effectiveness and practicality of ethical codes on behavior and add to employees' ethical awareness, training, and enforcement of codes of ethics.

In conclusion, there is a significant relationship between organizational ethical culture and ethical behavioral intentions of accounting/finance professionals in the insurance industry in U.S.A. Sims and Keon (2000, 1997) found written (formal) and unwritten (informal) organizational policies significantly affect employees' ethical decision-making, especially in the presence of intrapersonal role conflict. It is crucial for organizations to send the right message about its ethical culture to all employees. Ethical culture is a key determinant of ethical behavior (Key, 1999), and unethical culture is a spreading cancer that eventually devours great personalities. Jones (2002) concluded that ethics does not always pay but lack of it always hurts. The authors of this manuscript would like go one step further and, based on personal experiences, state that it pays mentally, physically, spiritually, and economically to be ethical.

\section{References}

1. Ajzen, I. (1991). "The theory of planned behavior". Organizational Behavior and Human Decision Processes 55: 179-211.

2. Ajzen, I. and Fishbein, M. (1980). "Understanding Attitudes and Predicting Social Behavior". Englewood Cliffs, New Jersey: Prentice-Hall Inc.

3. American Institute of Certified Public Accountants, (2003). "Research Examines Effects of Corporate Accounting Scandals on CPA Brand". [Online]. Available: http://www.aicpa.org/pubs/cpaltr/ jun2003/research.htm

4. Ampofo, A.; Mujtaba, B.; Cavico, F.; \& Tindall, L, (2004). Organizational Ethical Culture: A Significance Determinant of Ethical Behavior. Retrieved on July 24 from: http://www.aaahq.org/AM2004/cpe/ Ethics/Forum_01.pdf

5. Associated Press (2002). Enron investments cost state funds $\$ 63$ million. [Online]. Available: http://www.chron.com/cs/CDA/story.hts/special/enron/dec01/1187536

6. Bobek, D.D. and Hatfield, R.C. (2003). "An investigation of the theory of planned behavior and the role of moral obligation in tax compliance". Behavioral Research in Accounting. Vol. 15 pg 13, 26 pgs. Sarasota, Florida.

7. Brown, K.M. (1999). "Theory of Reasoned Action/Theory of Planned Behavior" (By Ajzen, I and Fishbein, M, 1975). University of South Florida, Community and Family Health. Florida, U.S.A.

8. Capps, T. E (2003). "Rebuilding trust in corporate America". Vital Speeches of the Day 69(9): 273.

9. Culp, C.L. and Hanke, S.H. (2003). "A Policy Analysis: Empire of the Sun: An Economic Interpretation of Enron's Energy Business". The Cato Institute. [Online]. Available: http://www.cato.org/pubs/pas/pa470es.html 
10. Dahlin, L.A. (2000). "An Empirical Study of Ethical and Unethical Decision-Making by Certified Management Accountants", A dissertation, submitted to Nova Southeastern University, Wayne Huizenga School of Business and Entrepreneurship. Michigan: Bell \& Howell Information and Learning.

11. Doering, R. R. (1998). Ethical decision-making in a business setting: Perceptions of employees. A dissertation. Texas A\&M University. Texas, U.S.A.

12. Doll, J. and Ajzen, I. (1992). Accessibility and Stability of Predictors in the Theory of Planned Behavior. Journal of Personality and Social Psychology. Vol. 63, Issue 5; page 754: Washington, U.S.A.

13. Dubinsky, A., and Loken, B. (1989). "Analyzing Ethical Decision Making in Marketing". Journal of Business Research. New York. Vol. 19, Iss. 2; p. 83 (25 pages)

14. Epstein, E.M. (1998). Business Ethics and Corporate Social Policy. Business \& Society. 37(1), 7-39.

15. Etherington, L. \& Hill, N. (1998). "Ethical Development of CMAs: A Focus on Non-Public Accountants in the United States". Research on Accounting Ethics, 4, 225-245.

16. Fraedrich, J. P. and Ferrell, O.C. (1992). "The Impact of Perceived Risk and Moral Philosophy Type on Ethical Decision Making in Business Organizations". Journal of Business Research 24(4): 283.

17. Finn, D., et al. (1988). "Ethical Problems in Public Accounting: The View from the Top". Journal of Business Ethics. Iss. 7, pgs 605-615

18. Geriesh, L. (2003). "Organizational culture and fraudulent financial reporting". The CPA Journal, Vol. 73, Issue 3, Page 28: New York.

19. Gibson, A.M. \& Frakes, A. H. (1997). "Truth or Consequences: A Study of Critical Issues in DecisionMaking in Accounting". Journal of Business Ethics, 16(2), 161-171.

20. Gunz, S. and McCutcheon, J. (1998). “Are academics committed to accounting ethics education?” Journal of Business Ethics. Vol.17, Iss. 11, p. 1145

21. Hoftstede, G. (1998). "Attitudes, values and organizational culture: Disentangling the concepts" Organization Studies.Vol. 19 , Iss. 3; p. 477 (17 pages): Berlin

22. Jones, D. (2002). Ethics don't always pay, but lack of them always hurts: Core values from top aid success. McLean, Virginia: U.S.A. TODAY.

23. Key, S. (1999). “Organizational Ethical Culture: Real or Imagined?” Journal of Business Ethics. 20, 217225, The Netherlands.

24. Key, S. (2002). "Perceived managerial discretion: An analysis of individual ethical intentions". Journal of Managerial Issues, 14, 2218-233.

25. McMurray, A. J. (2003). "The relationship between organizational climate and organizational culture". Journal of American Academy of Business, 3, 1/2: Cambridge, MA

26. Mintz, S.M. (1997). Cases in Accounting Ethics \& Professionalism. Third Edition. U.S.A.: Irwin/McGraw-Hill Company.

27. Mobley, S. F. (2002). The study of Lawrence Kohlberg's stages of moral development theory and ethics: Considerations in public administration practices. A dissertation. Nova Southeastern University. Florida, U.S.A.

28. Mujtaba, B., (1997). Business Ethics Survey of Supermarket Managers and Employees. UMI Dissertation Service. A Bell \& Howell Company. UMI Number: 9717687. Copyrighted by UMI. UMI: 300 North Zeeb Road. Ann Arbor, MI 48103. Phone: (313) 761-4700. (800) 521-0600.

29. Nunnally, L.C. (1978). Psychometric Theory, (2nd edition). New York: McGrawHill.

30. Page, A. (2003). "Putting your money where your morals are". Accounting and Business. London: The Chartered Association of Certified Accountants.

31. Peterson, D. K. (2002). "The relationship between unethical behavior and the dimensions of the ethical climate questionnaire". Journal of Business Ethics 41(4): 313.

32. Randall, D. M., Gibson, A. M. (1990). "Methodology in Business Ethics Research: A Review and Critical Assessment". Journal of Business Ethics. Dordrecht: Vol. 9, Iss. 6; p. 457 (15 pages)

33. Reigle, R. F. (2001). "Measuring Organic and Mechanistic Cultures". Engineering Management Journal, Vol.13, and No. 4: Alabama, U.S.A.

34. Sarbanes Oxley Act (2002). Sections 302 and 404.

35. Schein, E.H. (1992). Organizational Culture and Leadership: Jossey-Bass, page 12.

36. Schufter, D.E., and Ajzen, I. (1985). "Intention, perceived control, and weight loss; An application of the theory of planned behavior". Journal of Personality and Social Psychology, 49(3), 843-851. 
37. Sims, R.L. (2000). Bivariate Data Analysis: A Practical Guide. Nova Science Publishers, Florida.

38. Sims, R. L. and Keon, T.L. (1999). "The influence of organizational expectations on ethical decisionmaking conflict". Journal of Business Ethics 23(2): 219.

39. Sims, R., and Keon, T. (1997). "Ethical Work Climate as a Factor in the Development of Person Organization Fit". Journal of Business Ethics 16, 1095-1105

40. Smith, L.M. (2003). "A fresh look at accounting ethics (or Dr. Smith goes to Washington)". Accounting Horizons, Vol.17; Iss.1, pg 47-48. Sarasota, Florida.

41. Street, M.D. (1998). The effects of escalating commitment on ethical decision-making. A dissertation. Florida State University.

42. Trevino, L.K. et al (1986). "Ethical Decision-Making in Organizations. A Person-Situation Interactionist Model". Academy of Management Journal, 11 (3), 601-617.

Notes 